\title{
Crustal heterogeneity around the Nagamachi-Rifu fault, northeastern Japan, as inferred from travel-time tomography
}

\author{
Junichi Nakajima ${ }^{1}$, Akira Hasegawa ${ }^{1}$, Shigeki Horiuchi ${ }^{2}$, Kazuo Yoshimoto $^{3}$, Takeyoshi Yoshida ${ }^{4}$, and Norihito Umino ${ }^{1}$ \\ ${ }^{1}$ Research Center for Prediction of Earthquakes and Volcanic Eruptions, Graduate School of Science, Tohoku University, Sendai 980-8578, Japan \\ ${ }^{2}$ National Research Institute for Earth Science and Disaster Prevention, 3-1 Tennodai, Tsukuba-shi 305, Japan \\ ${ }^{3}$ Graduate School of Integrated Science, Yokohama City University, 22-2 Seto, Kanazawa-ku, Yokohama 236-0027, Japan \\ ${ }^{4}$ Institute of Mineralogy, Petrology and Economic Geology, Graduate School of Science, Tohoku University, Sendai 980-8578, Japan
}

(Received November 4, 2004; Revised February 9, 2006; Accepted March 15, 2006; Online published July 26, 2006)

\begin{abstract}
An $M=5$ earthquake occurred on September 15, 1998, in the Nagamachi-Rifu fault (NRF), northeastern Japan. In the aftermath of this event, many seismograph stations were constructed temporarily around the fault, forming a dense network of stations with a spatial separation of $5 \mathrm{~km}$. We report here our estimation of the threedimensional velocity structures of the $\mathrm{P}$ and $\mathrm{S}$ waves using arrival-time data recorded at these stations with the aim of understanding the heterogeneous structure around the NRF. Low-Velocity and high Poisson's ratio anomalies are imaged in the lower crust beneath the volcanic area, which are probably associated with the partially molten materials conveyed through the upwelling flow in the mantle wedge. A distinct low-velocity anomaly, which is explainable by the existence of $\mathrm{H}_{2} \mathrm{O}$-filled pores, is observed in the mid crust at the deeper extension of the NRF. Two low-velocity anomalies that are probably associated with the remnants of magmatic activity that formed the Shirasawa caldera and with the existence of thick late-Cenozoic sedimentary layers are observed at depths shallower than $10 \mathrm{~km}$ in the hanging wall of the NRF. Our results successfully characterize the major features of the complex velocity structure around the NRF, with implications for the existence of fluid-rich regions in the mid to lower crust.
\end{abstract}

Key words: seismic velocity structure, northeastern Japan, Nagamachi-Rifu fault, fluids, magma, caldera, active fault.

\section{Introduction}

Northeastern (NE) Japan is situated on the overriding plate of the NE Japan subduction zone, at a location where the Pacific plate is subducting at a rate of approximately 10 $\mathrm{cm} /$ year, with a convergence direction of $\mathrm{N} 65^{\circ} \mathrm{W}$ (DeMets et al., 1994). Many shallow earthquakes occur within the overriding continental plate, with most being concentrated in the areas along the volcanic front or the Ou Backbone range (Hasegawa et al., 2000). The Nagamachi-Rifu active fault system (hereafter denoted NRF) is one of the more active faults and runs through the center of the City of Sendai (Fig. 1(a)). The lateral extension of the NRF is approximately $20 \mathrm{~km}$ with a NE-SW strike and NW dipping, and the average slip rate of the fault is estimated to be approximately 0.7 m/1000 years (Active Research Fault Group, 1991). While the most recent activity of the fault is estimated to have been 2500-3000 years ago (Miyagi Prefectural Government, 2000), it has been reported that the NRF has a potential for a large earthquake with a magnitude of 7.0-7.5 (Miyagi Prefectural Government, 1997). Given that Sendai City has a population of more than one million, if the NRF slips and generates a large earthquake, the urban structures of the city will suffer serious damage.

Iio and Kobayashi (2003) and Iio et al. (2004a) hypothe-

Copyright (c) The Society of Geomagnetism and Earth, Planetary and Space Sciences (SGEPSS); The Seismological Society of Japan; The Volcanological Society of Japan; The Geodetic Society of Japan; The Japanese Society for Planetary Sciences; TERRAPUB sized that deep extensions of active faults exist beneath the seismogenic zone and that aseismic slip of these extensions controls the generation of large crustal earthquakes. They further suggested that a detailed investigation of deep structures around the active faults is of considerable importance for gaining an understanding of earthquake nucleation. Recent seismic studies around active faults (see, for example, Zhao et al., 1996, 2004; Thurber et al., 2003; Okada et al., 2005) have revealed a strong crustal heterogeneity in the earthquake source areas and shown that earthquake nucleation and rupture processes are closely related to the heterogeneous structure of fault zones.

A comprehensive joint research project entitled "Modeling of Deep Slip Processes in Seismogenic Inland Faults" was undertaken with the aim of enhancing current knowledge of the deep structure around the NRF (Ito, 2001). To facilitate the project, many temporary seismic stations were constructed and deployed, resulting in a dense seismograph network with a spatial separation of approximately $5 \mathrm{~km}$. The project also involved extensive experiments using active and passive recording of truck-mounted vibrators, natural earthquakes and 14 chemical explosions (80-120 kg) deployed around the NRF (see Hasegawa et al., 2001; Ikawa et al., 2001).

Comprehensive studies involving the collection of seismic and magnetotelluric (MT) data were carried out to elucidate the nature of the deep extension of the NRF. Nakamura et al. (2002) estimated the deep geometry of the NRF 


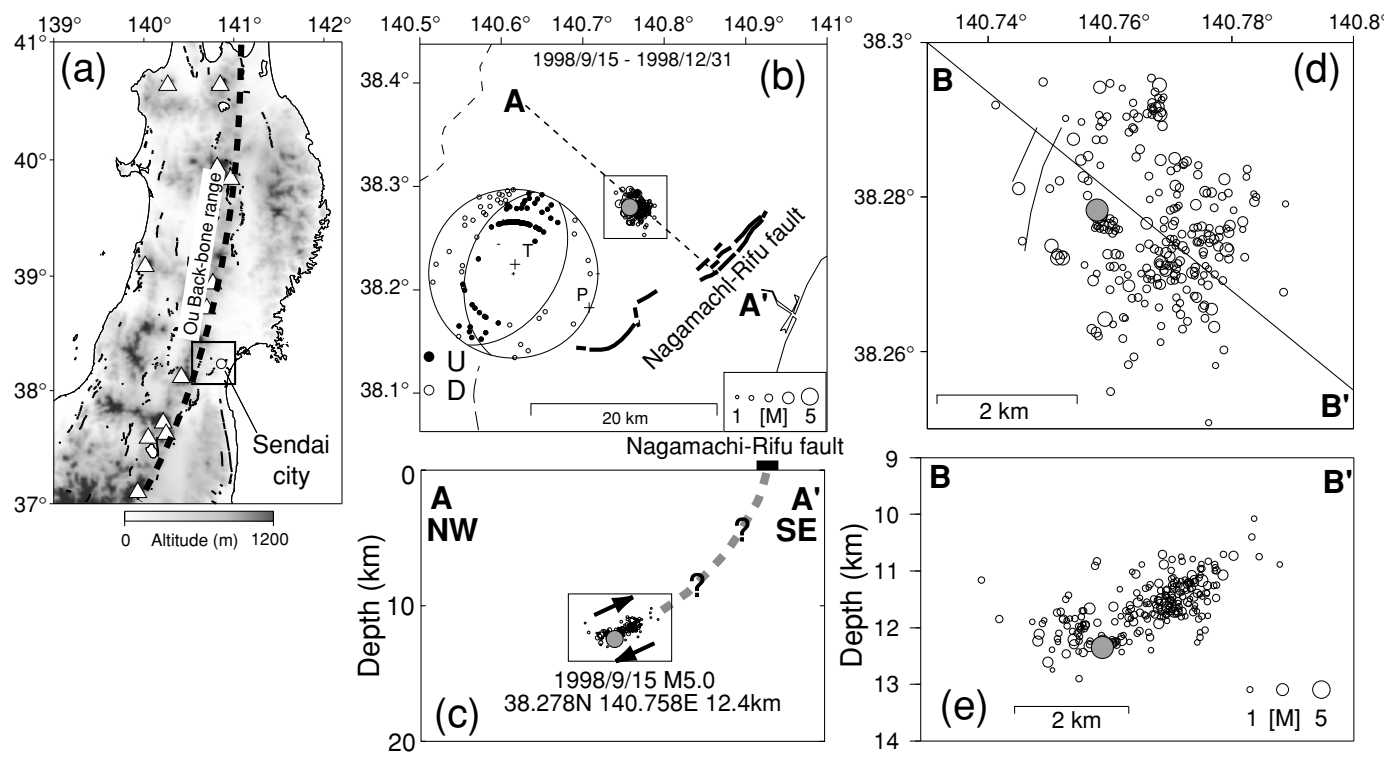

Fig. 1. (a) Topographical map showing the location of the study area. White triangles and black lines denote active volcanoes and active faults, respectively. Black thick dashed line represents the volcanic front. Rectangle shows the study area shown in (b). White circle in the rectangle indicates the location of the city of Sendai. Note that the volcanic front runs through the western part of the study area. (b) Epicenter distribution of the main shock and aftershocks. Gray and open circles show the main shock and aftershocks, respectively (after Umino et al., 2002a). The size of a circle is proportional to the magnitude of the event. Focal mechanism of the main shock projected on the lower focal hemisphere (Umino et al., 2002a) is shown. The NRF is marked by thick curves. Thin lines are other active faults. Broken lines represent prefectural borders. The area indicated by a rectangle is shown in (d). (c) Vertical cross section of the hypocenter distribution along the line A-A' in (b). The location of NRF is shown by a black bar at the top. Arrows show the fault motion of the main shock. The area indicated by a rectangle is shown in (e). (d) Magnification of the aftershock area shown by a rectangle in (b). Other symbols are the same as in (b). (e) Vertical cross section of the hypocenter distribution along the line B-B' in (d).

Table 1. Summary of the data sets used in the inversion.

\begin{tabular}{lccc}
\hline & Dataset 1 & Dataset 2 & Dataset 3 \\
\hline Period & Oct. 1996-Jan. 1998 & May 2001-Jul. 2002 & Oct. 1997-Jul. 1999 \\
Number of events & 144 & 349 & 4338 \\
Magnitude range & $0.2-3.8$ & $\geq 2.5$ & $\geq 2.0$ \\
Depth range, $\mathrm{km}$ & $0-20$ & $0-200$ & $0-200$ \\
Station & Around the NRF & Whole NE Japan/around the NRF & Whole NE Japan \\
Picking errors in & $0.05,0.2$ & $0.05,0.1-0.2$ & $0.05,0.1-0.2$ \\
P and S arrivals, $\mathrm{s}$ & & & \\
References & Yoshimoto et al. (2000) & Horiuchi et al. (2002) & Nakajima et al. (2001a) \\
\hline
\end{tabular}

from seismic array observations and proposed the possibility that the NRF has a low dip-angle in the mid crust as a detachment fault. Imanishi et al. (2002) attempted to deduce the distribution of $\mathrm{P}$-wave scatterers in the region from small aperture seismic array observations and found that the high scatter region spatially correlates with the distribution of microearthquakes, S-wave reflectors, and calderas. Ogawa et al. (2004) conducted a MT survey around the fault and detected two low-resistivity bodies: one is located at depths of 10-30 km below the volcanic front, and the other is located in the mid-crust zone below the surface trace of the NRF. Both of these bodies were interpreted to be fluidrich regions.

In this paper we report our application of seismic tomography to arrival-time data recorded at a dense seismic network constructed within the framework of the joint research project. Our objective was to determine a detailed threedimensional (3D) crustal structure around the NRF. Care- ful investigation of the 3D velocity structure may provide the key to our understanding of the heterogeneous structure associated with the NRF. We confined the region of investigation to an area with a lateral extent of approximately $40 \times 40 \mathrm{~km}$, within which a dense seismic network was established $\left(38.125^{\circ} \mathrm{N}\right.$ to $38.3875^{\circ} \mathrm{N}$ and $140.5625^{\circ} \mathrm{E}$ to $140.875^{\circ} \mathrm{E}$, with a depth range of $0-40 \mathrm{~km}$ ).

\section{Seismotectonic Setting}

Figure 1(a) shows the distribution of active faults and active volcanoes in NE Japan. The volcanic front runs through the middle of the NE Japan arc, and numerous active faults are concentrated on both sides of the volcanic front. On September 15, 1998, an earthquake with $\mathrm{M}=5.0$ occurred on the NRF and caused slight damage to some areas in the city of Sendai. Umino et al. (2002a) relocated the main shock and aftershocks by applying the homogeneousstation method and delineated the fault plane of this event, 


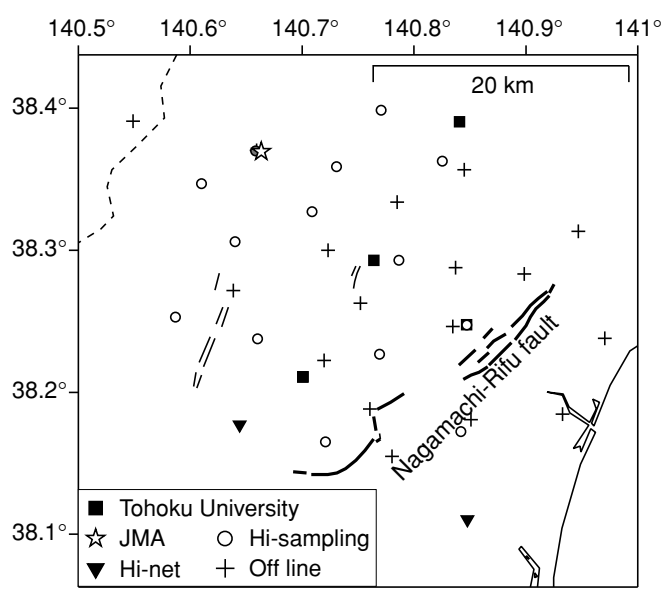

Fig. 2. Distribution of seismic stations around the NRF. Solid squares denote seismic stations of Tohoku University, open stars and solid reverse triangles denote permanent stations of JMA and NIED, open circles represent high frequency sampling stations (Horiuchi et al., 2002), and crosses indicate off-line stations deployed during 1996-1998 (Yoshimoto et al., 2000).
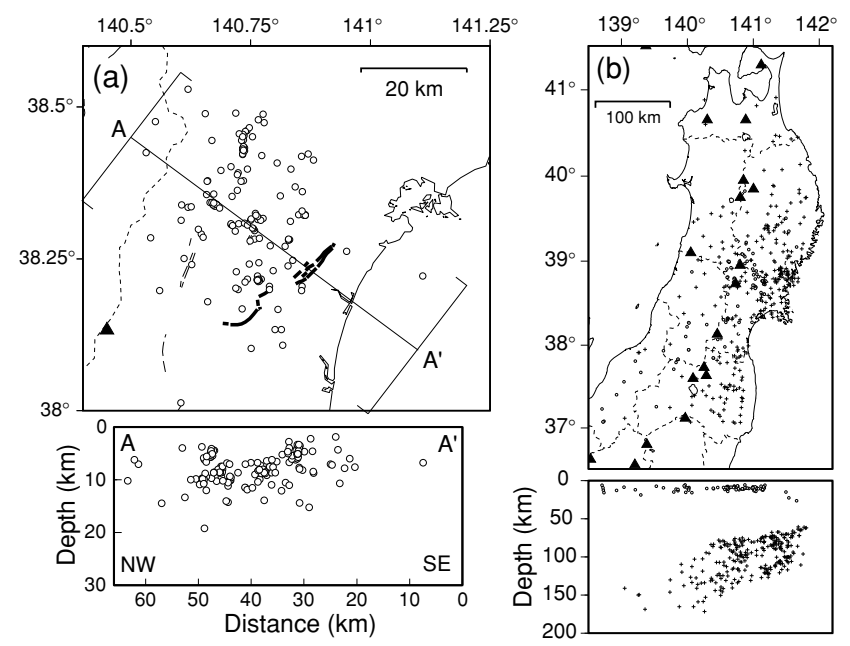

Fig. 3. Hypocenter distribution of earthquakes used for analysis in this study. (a) Map and cross-sectional views of 144 earthquakes that occurred in and around the study area (Yoshimoto et al., 2000). The black triangle shows an active volcano. (b) Map and cross-sectional views of earthquakes $(M>2.5)$ that occurred in NE Japan between May 2001 and July 2002 (total: 345 events). Open circles and crosses denote earthquakes with hypocentral depths less than and greater than $40 \mathrm{~km}$, respectively.

which dipped to the NW at an angle of approximately $30^{\circ}$ in the depth range of 10-13 km (Figs. 1(b)-(e)). The main shock occurred at a depth of approximately $12 \mathrm{~km}$, corresponding to the deeper limit of the distribution of aftershocks (Fig. 1(e)). The focal mechanism of the main shock was a reverse-fault type with a nearly horizontal P-axis (Fig. 1(b)) that was sub-parallel to the plate convergence direction (e.g., DeMets et al., 1994). Aftershocks were distributed on the fault plane in a $3 \times 3-\mathrm{km}$ region as shown in Fig. 1(d) and (e), and these were comparable with the spatial extent of the $M=5.0$ event rupture area estimated by waveform inversions (Okada et al., 2001). Umino et al. (2002a) suggested that this earthquake slipped at the deepest portion

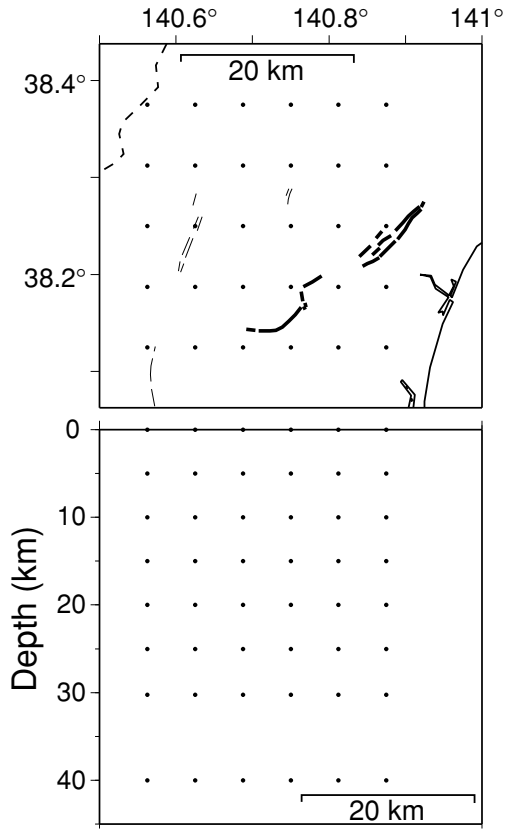

Fig. 4. Map and cross-sectional views of the configuration of grid nodes adopted in the inversion. Grid spacing in the horizontal direction is $0.0625^{\circ}(5-7 \mathrm{~km})$. Eight layers of grid nodes are set up at depths of 0 , $5,10,15,20,25,30$, and $40 \mathrm{~km}$.

Table 2. Average velocity at each depth.

\begin{tabular}{ccc}
\hline Depth, $\mathrm{km}$ & $\mathrm{P}$ wave velocity, $\mathrm{km} / \mathrm{s}$ & $\mathrm{S}$ wave velocity, $\mathrm{km} / \mathrm{s}$ \\
\hline 0 & 5.19 & 3.08 \\
5 & 5.51 & 3.19 \\
10 & 6.10 & 3.52 \\
15 & 6.28 & 3.63 \\
20 & 6.50 & 3.73 \\
25 & 6.62 & 3.75 \\
30 & 6.82 & 3.80 \\
40 & 7.43 & 4.12 \\
\hline
\end{tabular}

of the NRF, based on the geometrical relationship between the fault plane of the $M=5.0$ event and the surface trace of the NRF.

The geological structure around the fault is predominantly governed by the three late Cenozoic tectonic events, extensional deformation in the early to middle Miocene, formation of calderas in the late Miocene to Pliocene, and shortening deformation since the late Pliocene (see Sato, 1994; Sato et al., 2002 for details). The formation of early Miocene half grabens started approximately $21 \mathrm{Ma}$. The early half grabens were controlled by normal faults trending NNW-NW and were followed by younger grabens trending NE-SW. After the middle Miocene subsidence, which was associated with the formation of the northern Honshu rift system, the Ou Backbone range was gently uplifted. From 8 to $2 \mathrm{Ma}$, a large number of calderas were formed along the Ou Backbone range, including the western part of the region under investigation in this study. A majority of calderas are collapsed ones with diameters of approximately $10 \mathrm{~km}$ (Yoshida, 2001). This results in a complex crustal struc- 

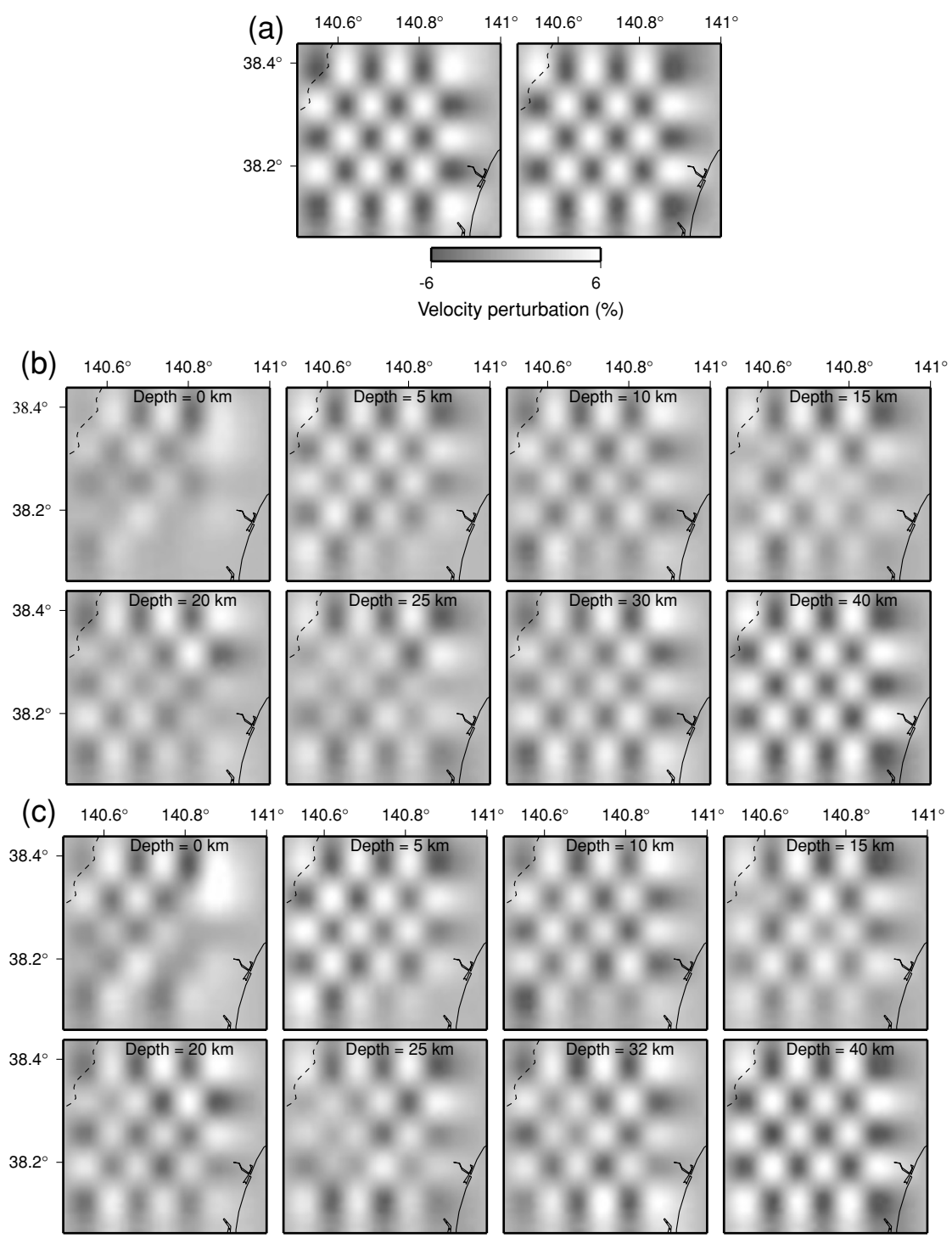

Fig. 5. (a) Synthetic models used in the checkerboard resolution test (CRT). Positive and negative velocity perturbations of $\pm 6 \%$ are assigned alternatively to every grid node in both the horizontal and vertical directions. Velocity perturbations shown in the left panel are assigned to depths of $0,10,20$, and $30 \mathrm{~km}$, while those in the right panel are for depths of 5, 15, 25, and $40 \mathrm{~km}$. (b) Results of CRT for the P wave. White and black colors represent high- and low-velocity anomalies, respectively, as shown in the scale in (a). (c) The same as in (b) but for the $\mathrm{S}$ wave.

ture in this area. Low Bouguer gravity anomalies related to calderas have also been identified (Komazawa and Mishina, 2002).

\section{Data and Methods}

Many temporary stations had been installed around the NRF under the framework of the joint research project as mentioned above. Figure 2 shows the distribution of stations around the fault, including off-line stations deployed temporarily between 1996 and 1998 (Yoshimoto et al., 2000), permanent and temporary stations established by Tohoku University, permanent stations of the Japan Meteorological Agency (JMA), Hi-net stations by the National Research Institute for Earth Science and Disaster Prevention (NIED), and high-frequency sampling stations (Horiuchi et $a l ., 2002)$. The total number of stations around the fault was 38 , and all the stations were equipped with three-component seismometers. The sampling rate is $1 \mathrm{kHz}$ for the highfrequency stations and $100 \mathrm{~Hz}$ for all other stations.
The earthquakes studied in our investigation are classified into three groups (Table 1). The first group consists of 144 shallow earthquakes, with magnitudes ranging from 0.2 to 3.8 , and was located by Yoshimoto et al. (2000). The distribution of the hypocenters of these earthquakes is shown in Fig. 3(a). Almost all of the hypocenters are located within the study area and clustered at depths shallower than $15 \mathrm{~km}$. The arrival-time data from these events were picked up at 16 off-line stations (crosses in Fig. 2), and these data play an important role in imaging the velocity structures at shallow depths. Maximum errors in picking up P- and $\mathrm{S}$-wave arrival times are considered to be approximately 0.05 and $0.2 \mathrm{~s}$ (Yoshimoto et al., 2000), respectively. The second group consists of 349 earthquakes with magnitudes $>2.5$ that occurred in NE Japan during the period from May 2001 to July 2002 (Fig. 3(b)). The arrival-time data of these events were picked up at both high-frequency sampling stations (circles in Fig. 2) and stations deployed by Tohoku University located within the study area (squares in Fig. 2) 


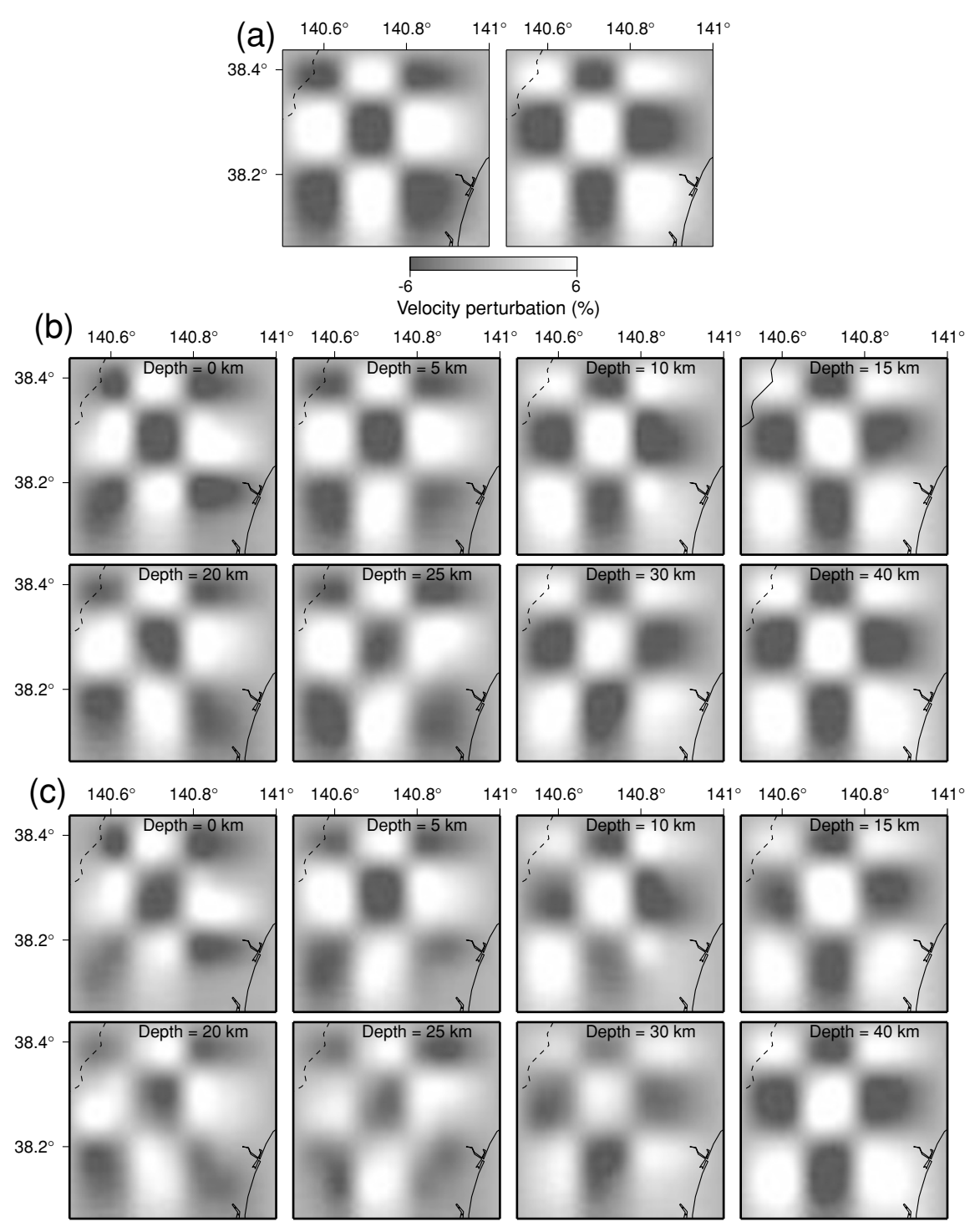

Fig. 6. (a) Synthetic models used in the CRT. Positive and negative velocity perturbations of $\pm 6 \%$ are assigned alternatively to every two grid nodes in the both horizontal and vertical directions. Velocity perturbations shown in the left panel are assigned to depths of $0,5,20$, and $25 \mathrm{~km}$, while those in the right panel are for depths of 10,15, 30, and $40 \mathrm{~km}$. (b) Results of CRT for the P wave. White and black colors represent high- and low-velocity anomalies, respectively, as shown in the scale in (a). (c) The same as in (b) but for the $\mathrm{S}$ wave.

as well as by stations deployed in the broader region of NE Japan (Nakajima et al., 2001a), using the same technique as that employed for routine monitoring by Tohoku University. The third group consists of 4338 earthquakes $(M>2.0)$ that occurred between October 1997 and July 1999 that were determined by the routine monitoring system at Tohoku University. The arrival-time data for these events were obtained at more than 200 stations deployed in the broader region of NE Japan (Nakajima et al., 2001a). This data set was also used in tomographic studies carried out by Nakajima et al. (2001a, b) and Nakajima and Hasegawa (2003). The recording system used in our investigation is the same that used for picking up the second data set; both data sets have average errors in picking up of $\mathrm{P}$ - and $\mathrm{S}$-wave arrival times of approximately $0.05 \mathrm{~s}$ and $0.15 \mathrm{~s}$, respectively. Rays derived from the latter two data sets propagate at deeper parts and edges of the study area, thus providing good constraints on the velocity structures in such regions, which cannot be well resolved by using the arrival-time data from source and receiver pairs, both located within the study area. This methodology provided a good ray coverage throughout the study area. All earthquakes were relocated prior to the inversion with the three-dimensional (3D) velocity model of Nakajima et al. (2001a) in which we used exactly the same method as that used for estimating the velocity structure in this study.

The inversion method developed by Zhao et al. (1992) was adopted, taking into account three seismic discontinuities - the Conrad (Zhao et al., 1990) and Moho discontinuities (Zhao et al., 1990; Nakajima et al., 2002), and the upper plate boundary of the subducted Pacific slab (Hasegawa et al., 1994; Zhao et al., 1997). The welldetermined 3D P- and S-wave velocity structures for NE Japan (Nakajima et al., 2001a) were adopted for the initial velocities within and outside the study area, which enabled us to use arrival-time data whose rays propagate outside the study area. In this study the 3D P- and S-wave velocity structures in the area extending from $38.125^{\circ} \mathrm{N}$ 

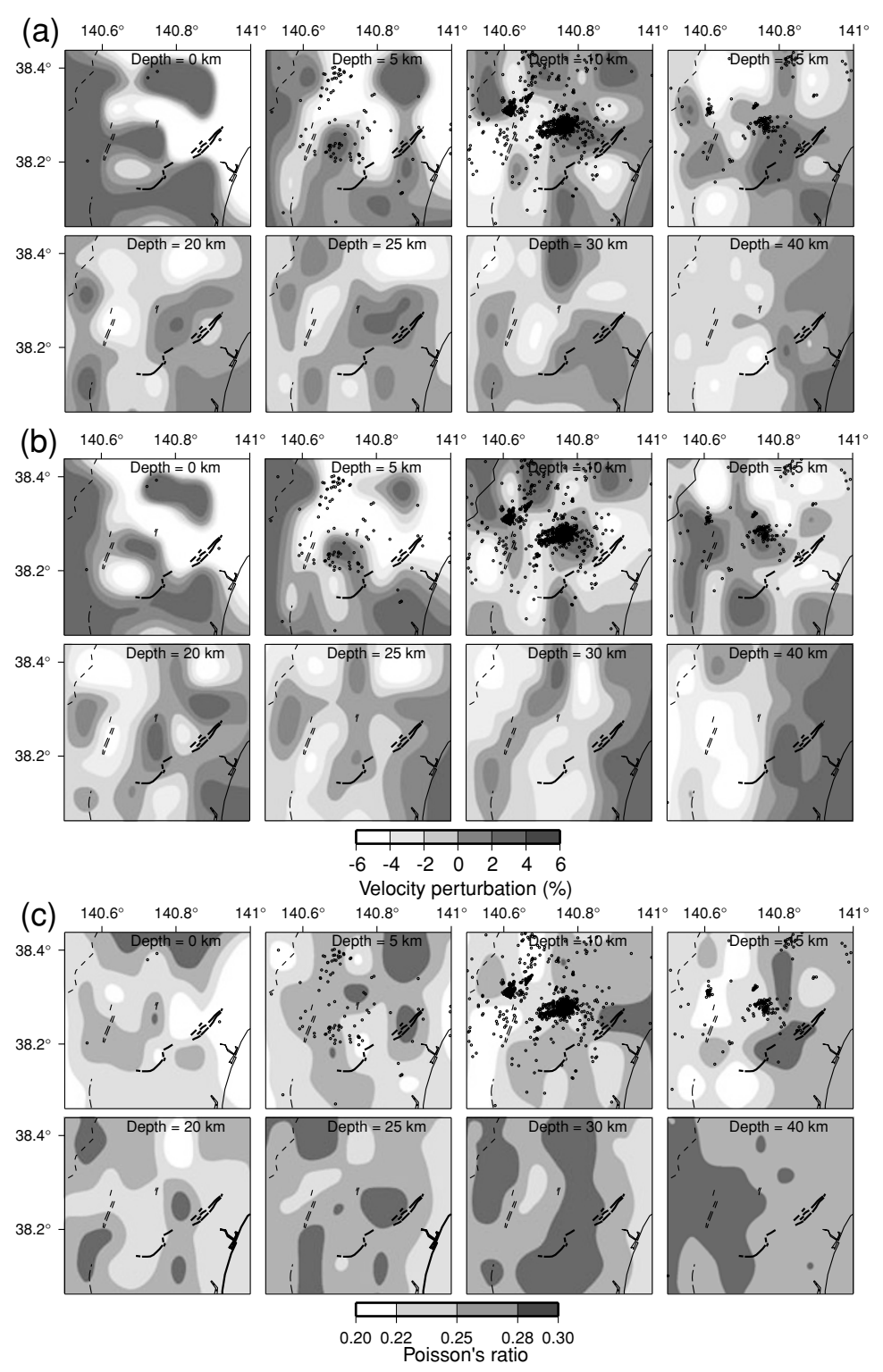

Fig. 7. Map showing (a) P-wave, (b) S-wave velocity perturbations, and (c) Poisson's ratio. Velocity perturbations are the deviation from the average velocity at each depth (Table 2). White shows low velocity and low Poisson's ratio, and black shows high velocity and high Poisson's ratio. In each figure, earthquakes that occurred within $\pm 2.5 \mathrm{~km}$ from the depth are shown by circles.

to $38.3875^{\circ} \mathrm{N}$ and $140.5625^{\circ} \mathrm{E}$ to $140.875^{\circ} \mathrm{E}$ with a depth range of $0-40 \mathrm{~km}$ were estimated with those fixed outside the area. This method is similar to those successfully adopted by Nakajima et al. (2001b) and Nakajima and Hasegawa (2003). Horizontal grid nodes were spaced at intervals of 5-7 km, and vertical grid nodes were set at depths of $0,5,10,15,20,25,30$, and $40 \mathrm{~km}$ (Fig. 4). The total number of rays intersecting the study area was 26,457 and 14,351 for $\mathrm{P}$ and $\mathrm{S}$ waves, respectively.

\section{Results and Synthetic Tests}

To ascertain the adequacy of ray coverage and the reliability of obtained images, we carried out checkerboard resolution tests (CRT). In these tests, positive and negative velocity perturbations of $6 \%$ were assigned alternately to grid nodes for both the horizontal and vertical directions, and travel times for this model were calculated to generate synthetic data. Synthetic data were constructed from the same source-receiver geometry as those used for the observations. Random noises corresponding to reading errors (a standard deviation of $0.1 \mathrm{~s}$ for the $\mathrm{P}$ wave and $0.2 \mathrm{~s}$ for the $\mathrm{S}$ wave) were added to the synthetic travel-time data. Figure 5 shows the results of the CRT for $\mathrm{P}$ and $\mathrm{S}$ waves at depths of $0,5,10,15,20,25,30$, and $40 \mathrm{~km}$. The patterns were recovered for both $\mathrm{P}$ and $\mathrm{S}$ waves. Another CRT test was performed in the same manner, but for a different grid spacing (Fig. 6). Positive and negative velocity perturbations of $6 \%$ were assigned alternately to every two grid nodes in both the horizontal and vertical directions. The results show that the initial checkerboard pattern is considerably well retrieved for all depths. These tests demonstrate that the data is sufficient to resolve velocity anomalies comparable to the lateral extent of one or two grid nodes.

The final results were obtained after six iterations. The root mean square (rms) of arrival-time residuals for the initial model, which were $0.16 \mathrm{~s}$ for the $\mathrm{P}$ wave and $0.32 \mathrm{~s}$ 
Table 3. Characteristics of five prominent anomalies discussed in the text.

\begin{tabular}{lccccc}
\hline & Anomaly 1 & Anomaly 2 & Anomaly 3 & Anomaly 4 & Anomaly 5 \\
\hline Vp & $-3 \sim 0 \%$ & $\sim-10 \%$ & $-8 \sim-6 \%$ & $\sim-10 \%$ & $\sim 3 \%$ \\
Vs & $\sim-6 \%$ & $\sim-10 \%$ & $\sim-10 \%$ & $-10 \%$ & $-3 \sim 0 \%$ \\
Poisson's ratio & High & Moderate & Moderate to high & Low to moderate
\end{tabular}
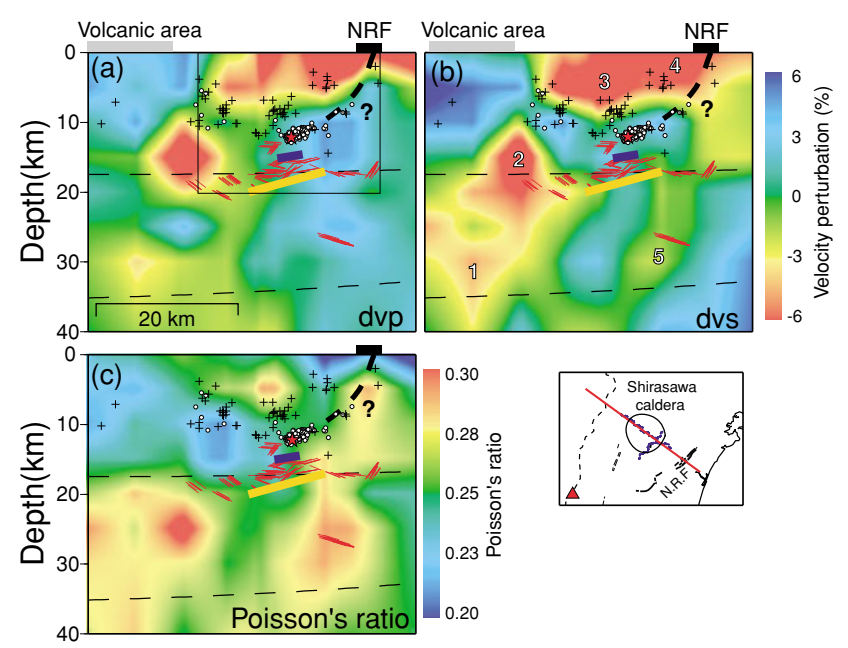

Fig. 8. Vertical cross sections of (a) P-wave and (b) S-wave velocity perturbations, and (c) the Poisson's ratio along the red line shown in the insert map. Black bars on the top of each figure show the surface trace of the NRF. Gray bars on the top of (a) and (b) represent the volcanic area. Crosses and white circles indicate shallow microearthquakes determined by Yoshimoto et al. (2000) (dataset 1) and Umino et al. (2002a) (earthquakes shown in Fig. 1), respectively. The hypocenter of the $M=5.0$ earthquake is indicated by a red star. Red lines represent distinct S-wave reflectors (bright spots) detected by Hori et al. (2004). Blue and yellow lines denote the S-wave reflector identified by Umino et al. (2002b). The S-wave reflector indicated by a blue line is filled with $\mathrm{H}_{2} \mathrm{O}$ (Umino et al., 2002b). Thick black broken lines represent the inferred geometry of the NRF. Broken lines denote the seismic velocity discontinuities adopted in the inversion. The rectangle in (a) denotes the area shown in Fig. 11. Blue lines in the inset map represent the profiles of the reflection survey (Ikawa et al., 2001), and the black circle denotes the location of the Shirasawa caldera (Yoshida, 2001). The five prominent velocity anomalies discussed in the text are labeled (1), (2), (3), (4), and (5) in (b).

for the $S$ wave, were reduced to $0.13 \mathrm{~s}$ and $0.28 \mathrm{~s}$, respectively, upon optimization. The velocity perturbations shown hereafter are the derivation from the average velocities calculated from the inverted 3D velocities at each depth (Table 2). Figure 7 depicts the map showing P- and S-wave velocity perturbations and the Poisson's ratio. The results show a highly heterogeneous structure around the NRF. Distinct low-velocity areas are imaged at depths of 0 and $5 \mathrm{~km}$ in the north and the east of the NRF, while high-velocity areas are predominantly imaged at the western part of the study area. At a depth of $10 \mathrm{~km}$, a velocity anomaly with low $\mathrm{Vp}$ and low-Poisson's ratio is seen in the western part of the study area. A high velocity anomaly is detected around the aftershock area of the $M=5.0$ event. Isolated low-velocity areas are imaged in the north of the study area at depths ranging from 15 to $30 \mathrm{~km}$; below $15 \mathrm{~km}$ areas with high-Poisson's ratio are distributed near the surface trace of the NRF. At a depth of $40 \mathrm{~km}$ a prominent low-Vs and high Poisson's

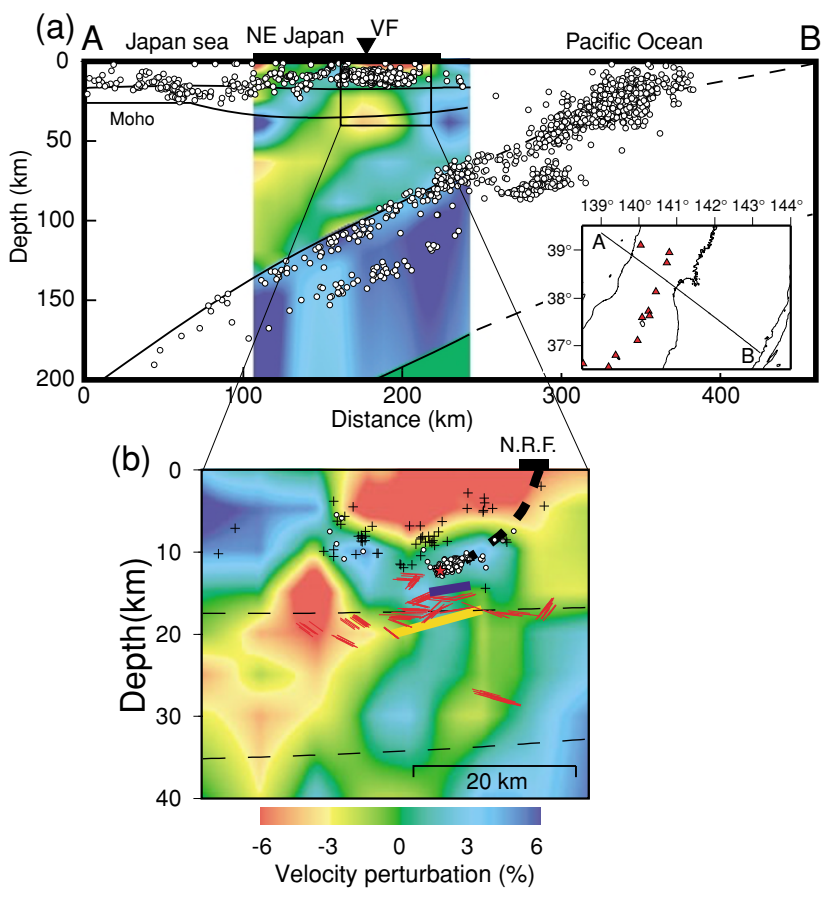

Fig. 9. (a) Vertical cross section of S-wave velocity perturbation along the line shown in the insert map (after Nakajima et al., 2001a). White circles and black lines show microearthquakes and seismic velocity discontinuities, respectively. A black bar and a reverse triangle at the top denote the land area and the location of the volcanic front (VF), respectively. Red triangles in the insert map show active volcanoes. A rectangle indicates the area shown in (b). (b) Vertical cross section of $\mathrm{S}$-wave velocity perturbation (the same as in Fig. 8(b)). Symbols are the same as in Fig. 8.

ratio body exits in the western part of the study area where the volcanic front runs through (Fig. 1).

Figure 8 shows vertical cross sections of $\mathrm{P}$ - and $\mathrm{S}$-wave velocity perturbations and Poisson's ratio along the profile, which is sub-perpendicular to the surface trace of the NRF. Velocity anomalies described in the map are wellcharacterized in the cross section. For the discussion of velocity anomalies associated with the NRF, we defined five prominent velocity anomalies: (1) low-velocity and highPoisson's ratio body at depths of $20-40 \mathrm{~km}$ beneath the volcanic area; (2) low-velocity anomaly in both $\mathrm{P}$ and $\mathrm{S}$ waves at a depth of approximately $15 \mathrm{~km}$ on a deeper extension of the aftershock area, with moderate Poisson's ratio; (3) a prominent low-velocity anomaly in both $\mathrm{P}$ and $\mathrm{S}$ waves with slightly high Poisson's ratio down to depths of 5-10 $\mathrm{km}$ in the hanging wall of the NRF; (4) a low-Vp and lowVs anomaly with low-to-moderate Poisson's ratio close to the surface trace of the NRF; (5) a relatively high Poisson's ratio in the footwall of the NRF at depths of $15-35 \mathrm{~km}$. Major features of these velocity anomalies are also summarized 

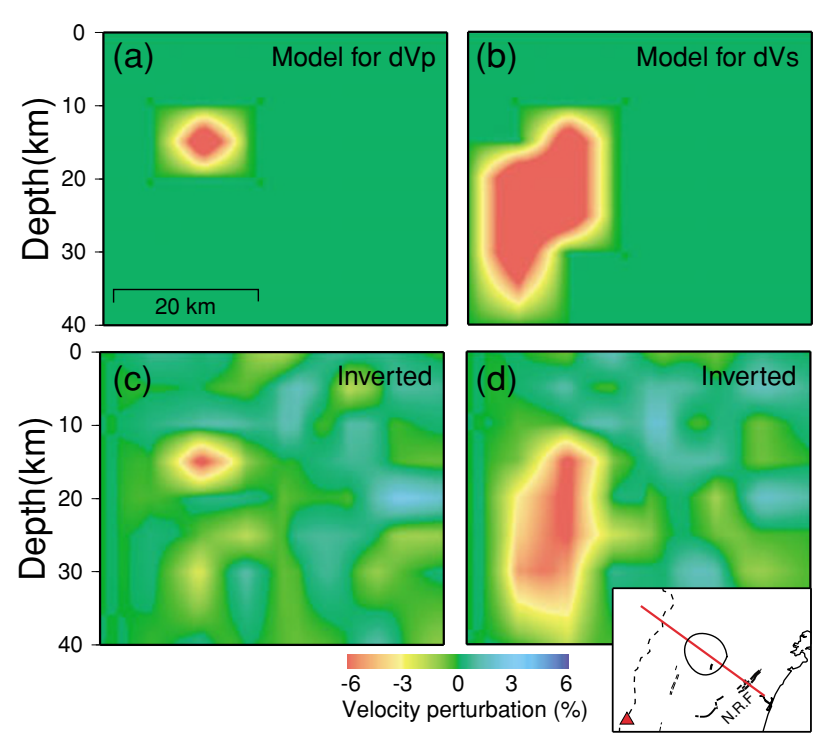

Fig. 10. Results of a reconstruction test for anomalies (1) and (2) along the red line in the insert map (the same as the line in Fig. 8). Input model for (a) $\mathrm{P}$ and (b) $\mathrm{S}$ waves, and inverted model for (c) P and (d) S waves. The scale for velocity perturbation is shown at the bottom.

in Table 3.

\section{Interpretations}

Seismic velocity varies depending on physical aspects, of which saturation condition, temperature, and ambient pressure play an important role. The variations in the ambient pressure would be negligible when the deviation from the average velocity at each depth is used for characterizing the velocity anomaly. It is considered that, for crustal rocks, the high- and low-temperature anomalies result in low- and high-velocity anomalies, respectively, with little effect on Poisson's ratio (Ji et al., 2002), which indicates that a velocity anomaly with a considerable change in the Poisson's ratio cannot be explained by the thermal anomaly alone.

It is known that the effect of fluids on seismic velocity depends on the kind of fluids and the shape of the fluidfilled pores (e.g., Takei, 2002). The shape of fluid-filled pores can be represented by an "equivalent aspect ratio" or "effective aspect ratio", which is defined as the ratio of the minor radius to the major radius of the fluid-filled oblate spheroidal pores. The existence of melt-filled pores apparently lowers seismic velocity and increases the Poisson's ratio-independent of the shape of the pores. The existence of $\mathrm{H}_{2} \mathrm{O}$-filled pores has, however, a different effect on seismic velocity - in particular on Poisson's ratio-which depends on the shape of the pores (Takei, 2002). The $\mathrm{H}_{2} \mathrm{O}$ filled pore with an aspect ratio smaller than approximately 0.1 increases Poisson's ratio with decreasing seismic velocity, which is an effect identical to that of melt-filled pores. On the other hand, the $\mathrm{H}_{2} \mathrm{O}$-filled pores with an aspect ratio larger than approximately 0.1 lowers Poisson's ratio slightly with decreasing seismic velocity.

\subsection{Deep structure around the Nagamachi-Rifu fault}

An inclined low-velocity zone has been imaged in the mantle wedge of NE Japan by local travel-time tomography (Hasegawa et al., 1991; Zhao et al., 1992; Nakajima et al.,

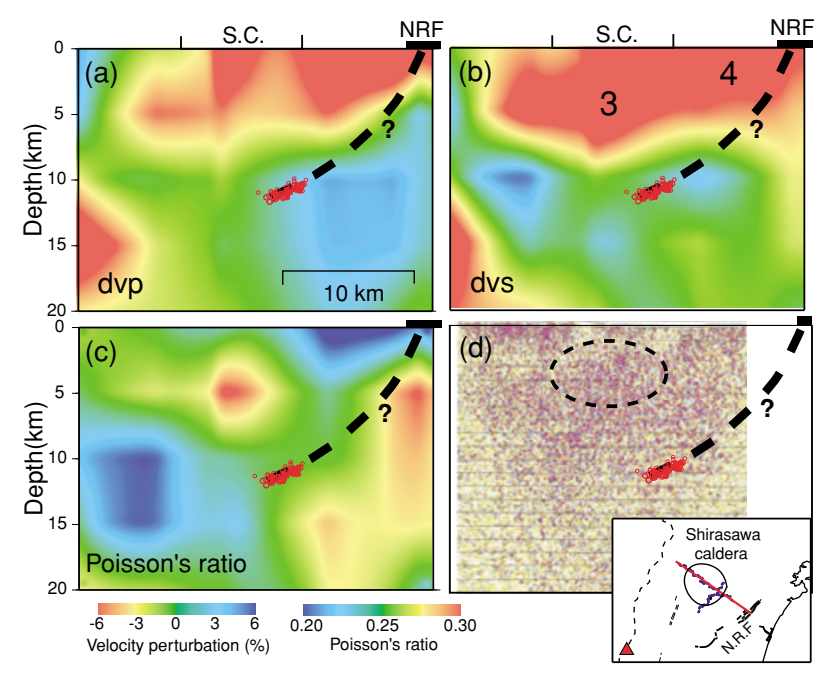

Fig. 11. Vertical cross sections of (a) P-wave and (b) S-wave velocity perturbations, and (c) the Poisson's ratio along the line shown in the insert map, which corresponds to the area outlined in Fig. 8(a). (d) Deep common midpoint reflection profile (Ikawa et al., 2001) for the same profile as in (a)-(c). The rim of the Shirasawa caldera (S.C.) is shown by ticks in (a) and (b). A black broken circle in (d) indicates a remarkable group of reflectors (after Sato et al., 2002). Red circles show the aftershock distribution of the $\mathrm{M}=5.0$ earthquake (Umino et al., 2002a). Other symbols are the same as in Fig. 8.

2001a). The zone is distributed sub-parallel to the down-dip direction of the subducted slab as a single inclined sheet and is considered to be the upwelling (return) flow portion that is mechanically induced by viscous coupling between the subducted and overriding plates (Hasegawa and Nakajima, 2004). A quantitative analysis of the inclined low-velocity zone (Nakajima et al., 2005) reveals the existence of meltfilled pores in it and interprets the inclined low-velocity zone to be the main source of arc magmas.

Figure 9(a) shows a large-scale cross-sectional view of the S-wave velocity along the line shown in the insert map (after Nakajima et al., 2001a). The above-mentioned inclined low-velocity zone is seen in the mantle wedge and crosses the Moho beneath the volcanic front. The velocity image obtained in this study (Fig. 9(b)) shows a small-scale heterogeneity for the crust. The low-velocity zone imaged in the lower crust (anomaly 1 in Fig. 8) appears to be connected to the inclined low-velocity zone in the mantle, with implications that this anomaly is closely associated with partially molten materials conveyed through the upwelling flow.

Anomaly (1) is a region of low Vs and high Poisson's ratio. Such anomalies have been commonly observed in the lower crust in other parts of NE Japan and interpreted to be partially molten materials (Nakajima et al., 2001a, b; Nakajima and Hasegawa, 2003). Although the geotherm in this area is not well known, it is generally considered that temperatures at the lower crust near the volcanic front exceed the wet solidus of basalt and andesite (Yoshida, 2001). Hence, it is likely that partially molten materials are distributed at this depth, thereby causing anomaly (1). The two-dimensional finite element modeling by lio et al. (2004b) showed that the observed surface deformations by GPS can be explained by models with a weak zone in the 
lower crust, leading these authors to suggest that this weak zone plays an important role in the stress accumulation process on the NRF. Anomaly (1) could act like such a zone.

Anomaly (2) exhibits a moderate Poisson's ratio despite prominent low-Vp and low-Vs anomaly. Many S-wave reflectors and scatterers, which are considered to be another aspect of fluid reservoirs, have been found beneath the study area (Imanishi et al., 2002; Umino et al., 2002b; Hori et al., 2004), as is shown in Fig. 8. In addition, a highly conductive zone imaged around this anomaly is interpreted to be a fluid-rich region (Ogawa et al., 2004), and the mutual analysis of resistivity and seismic velocity data suggests the presence of regions of high pore connectivity at the NW part of the deep extension of the NRF (Pervukhina et al., 2004). Hence, we infer that the existence of $\mathrm{H}_{2} \mathrm{O}$-filled pores with a relatively large aspect ratio $(>0.1)$ can be a plausible candidate for this anomaly. The $\mathrm{H}_{2} \mathrm{O}$ responsible for anomaly (2) might be expelled from the partially molten materials causing anomaly (1).

The presence of partially molten materials and $\mathrm{H}_{2} \mathrm{O}$ at the lower- to mid-crustal levels could promote deformation at that depth under distinctive compression in the E-W or ESE-WNW direction (Nishimura et al., 2004), thereby causing a stress concentration in the seismogenic zone above it (Hasegawa et al., 2000, 2005). This interpretation coincides with high seismic activity in the hanging wall of the fault (Fig. 8). Fluid-rich regions have been found, for example, in source areas of the 1995 Kobe earthquake $(M=7.2)$ (Zhao et al., 1996), the 1999 Chi-Chi earthquake ( $M=7.6)$ (Chen et al., 2001), the 2000 western Tottori earthquake ( $M=7.3)$ (Zhao et al., 2004), and along the San Andreas Fault (e.g., Johnson and McEvilly, 1995; Thurber et al., 2003). These observations suggest the importance of fluids on stress accumulation processes for the occurrence of crustal earthquakes.

A high-temperature anomaly may be another possible candidate responsible for anomaly (2). It is known that the decrease in P-wave velocity for granite is about $0.5-$ $2.4 \%$ with a $100^{\circ} \mathrm{C}$ increase in temperature (Christensen and Mooney, 1995; Christensen, 1996), indicating that temperatures of several hundreds of degrees higher than the surrounding region are required for the generation of the observed Vp anomaly. Such high temperatures would, however, exceed the solidus of granite and cause partial melting, thereby contradicting the moderate value of the Poisson's ratio. Thus, it is unlikely that only the high-temperature condition can be attributed to anomaly (2), although hightemperature conditions may also contribute in part.

Anomalies (1) and (2) are the keys in understanding the deep structure of the NRF. We carried out yet another sensitivity test - a reconstruction test-for further assessment of the reliability of these anomalies. Figures 10(a) and (b) show synthetic models for $\mathrm{P}$ and $\mathrm{S}$ waves, respectively, for the same profiles as shown in Fig. 8. Different synthetic models were used for $\mathrm{P}$ and $\mathrm{S}$ waves, corresponding to the obtained velocity structures (compare Fig. 8(a) for the $\mathrm{P}$ wave and 8 (b) for the $\mathrm{S}$ wave). In this test a velocity anomaly of $-6 \%$ was assigned to the corresponding grid nodes. The calculation of the synthetic travel-time and the inversion method are the same as those for the CRT. The results (Fig. 10(c) and (d)) show that the assumed velocity anomalies are well recovered although their shapes are slightly distorted. This test demonstrates again that velocity anomalies (1) and (2) at the deeper extension of the NRF are reliable and that they are not artifacts resulting from poor resolution.

The cause of anomaly (5) is somewhat ambiguous. It is difficult to account for this anomaly by the presence of fluids and/or by thermal heterogeneity since the anomaly shows an opposite variation in $\mathrm{P}$ and $\mathrm{S}$ waves (high $\mathrm{Vp}$ and low Vs) with a high Poisson's ratio. One possible explanation is the existence of more mafic and anhydrous plutonic rocks, such as gabbro and diorite, than the surroundings, which are composed of amphibole-bearing metamorphic and plutonic rocks (Yoshida, 2001). Andesite and basalt produced by Miocene magmatic activity have been found at the surface to the south of this profile (Geological Survey of Japan, 1992). A mafic rock body that intruded from deeper levels as a result of Miocene magmatic activity might be distributed in the footwall of the NRF. However, this interpretation needs further observational confirmation.

\subsection{Shallow structure around the Nagamachi-Rifu fault}

Figure 11 shows the magnification for anomalies (3) and (4) in Fig. 8, together with the deep common midpoint (CMP) reflection profile (Ikawa et al., 2001). A possible explanation for anomaly (3) with low Vp, low Vs, and high Poisson's ratio can be the existence of remnants of magmatic activity that formed the calderas during the period 8$2 \mathrm{Ma}$ (Yoshida, 2001). The profile shown in Figs. 8 and 11 crosses the Shirasawa caldera (ticks in Figs. 11(a) and (b)), which was formed in the late Miocene. It is considered that, at that time, magma chambers with lateral extents comparable to the dimension of the calderas existed (Yoshida, 2001). The CMP reflection profile (Fig. 11(d)) reveals a remarkable group of reflectors with diameters of approximately $8 \mathrm{~km}$ at depths of 2-5 km (an area indicated by the broken black circle), and the location is in agreement with the Shirasawa caldera. Sato et al. (2002) interprets this group of reflectors as a plutonic rock within the Shirasawa caldera that worked as a source reservoir for the felsic caldera. Similar low-velocity anomalies have been imaged around the Onikobe volcanic area in NE Japan (Nakajima and Hasegawa, 2003), where an abundance of calderas has been found. Thus, it is possible that a plutonic rock with a relatively large amount of fluids and with higher temperatures than that of the surrounding parts results in anomaly (3). If anomaly (3) is caused by the existence of $\mathrm{H}_{2} \mathrm{O}$ and locally higher temperatures, brittle failure is unlikely to occur in that region, which agrees well with the occurrence of few microearthquakes within the anomaly (3) (Fig. 8).

Anomaly (4), giving rise to low $\mathrm{Vp}$ and low $\mathrm{Vs}$, may be explained by historical inversion tectonics. It is known that the NRF was formerly activated as a normal fault in the Miocene and then reactivated as a reverse fault since the late Pliocene (e.g. Sato et al., 2002). Faults with reactivation have also been reported in the eastern part of the Japan Sea (Okamura et al., 1995) and in the Sendai Bay area (Nakamura, 1992). If the NRF had been activated as a normal 
fault, the footing wall could be shifted upward relative to the hanging wall and then the hanging wall could be covered with thicker late Cenozoic sediments than the footwall due to the fault movement. The effect can result in the hanging wall having a lower velocity than the footwall. The existence of thicker late Cenozoic sediments in the hanging wall is consistent with the low-Bouguer gravity anomaly (Komazawa and Mishina, 2002). Similar low-velocity anomalies probably related to the inversion tectonics have been imaged in the hanging wall of the Ishinomaki-wan fault (Okada, 2003), located approximately $50 \mathrm{~km} \mathrm{NE}$ away from the NRF, and in the hanging wall of the fault where the 2004 Mid-Niigata prefecture earthquake $(M=6.8)$ occurred (Okada et al., 2005). Both faults had activated as normal faults in the Miocene and reactivated as reverse faults under the current compressional stress regime. Hence, we infer that the late Cenozoic sedimentary layers formed prior to the reactivation to reverse faulting are the major contributions to the low velocity anomaly (4).

\section{Conclusions}

The 3D seismic velocity structure around the NRF was estimated by travel-time tomography. A dense seismic network has been temporarily deployed since the occurrence of $\mathrm{M}=5.0$ event. Arrival-time data obtained at these stations were used to estimate the velocity structure around the NRF together with those obtained at stations located over a wider area of NE Japan. The total number of rays intersecting the study area was 26,457 and 14,351 for $\mathrm{P}$ and $\mathrm{S}$ waves, respectively.

A low-Vs and high Poisson's ratio anomaly was imaged in the lower crust in the western part of the profile, which possibly can be attributed to partially molten materials, similar to those observed in other parts of NE Japan. A distinct low-velocity anomaly with moderate Poisson's ratio was detected at the deeper extension of the NRF, explainable by the existence of $\mathrm{H}_{2} \mathrm{O}$-filled pores with large aspect ratios. This interpretation does not contradict the detection of S-wave reflectors (bright spots) below the fault (Umino et al., 2002b) and a high conductivity zone around the fault (Ogawa et al., 2004). We infer that the $\mathrm{H}_{2} \mathrm{O}$ expelled from the partially molten materials in the lower crust is localized and causes low-velocity and high-conductive anomalies. A low-Vp, low-Vs, and slightly high Poisson's ratio anomaly were also imaged at depths down to $5-10 \mathrm{~km}$, within which only few microearthquakes occurred. Fluid-rich plutonic rocks with higher temperatures that are the remnants of the magmatic activity forming calderas in the period 8-2 Ma might be responsible for this anomaly. The low-velocity anomaly near the surface trace of the NRF is probably associated with a thick late Cenozoic sedimentary pile that was formed prior to reactivation of the fault.

This study successfully reveals major features of the complex velocity structure around the NRF, NE Japan, and it is hoped that the results obtained herein will allow the development of better models of this fault. Further work could possibly involve a waveform modeling as well as a quantitative interpretation of velocity anomalies. These are, however, beyond the scope of this paper.
Acknowledgments. The authors would like to thank H. Hamaguchi, H. Fujimoto, M. Ohtake, H. Sato, and the members of the Research Center for the Prediction of Earthquakes and Volcanic Eruptions of Tohoku University for valuable discussions. D. Zhao provided the software for tomographic inversion. Two anonymous referees provided thoughtful comments that led to improvements of the manuscript. Our appreciation is extended to the staff of $\mathrm{Hi}-$ rosaki University, the University of Tokyo, the Japan Meteorological Agency, and the National Research Institute for Earth Science and Disaster Prevention for allowing us to use the data from their stations. All figures in this paper were plotted using GMT (Wessel and Smith, 1998). This work was conducted as a part of the 'Comprehensive Research on Slip and Flow Processes in and below the Seismogenic Region' supported by the Special Coordination Fund of the Ministry of Education, Culture, Sports, Science and Technology of Japan.

\section{References}

Active Fault Research Group, Active Faults in Japan, revised ed., University of Tokyo Press, Tokyo, 437 pp., 1991.

Chen, C., W. Wang, and T. Teng, 3D velocity structure around the source area of the 1999 Chi-Chi, Taiwan, earthquake: before and after the main shock, Bull. Seismol. Soc. Am., 91, 1013-1027, 2001.

Christensen, N. I., Poisson's ratio and crustal seismology, J. Geophys. Res., 101, 3139-3156., 1996.

Christensen, N. I. and W. D. Mooney, Seismic velocity structure and composition of the continental crust: A global view, J. Geophys. Res., 100, 9761-9788, 1995.

DeMets, C., R. G. Gordon, D. F. Argus, and S. Stein, Effect of recent revisions to the geomagnetic reversal time scale on estimates of current plate motions, Geophys. Res. Lett., 21, 2191-2194, 1994.

Geological Survey of Japan, Geologic Atlas of Japan, Asakura Publishing Company, Ltd., Tokyo, 140 pp., 1992.

Hasegawa, A. and J. Nakajima, Geophysical constraints on slab subduction and arc magmatism, in The State of the Planet: Frontiers and Challenges in Geophysics, Geophys. Monogr. Ser., vol. 150, pp. 81-94, AGU, Washington, D.C., 2004.

Hasegawa, A., D. Zhao, S. Hori, A. Yamamoto, and S. Horiuchi, Deep structure of the northeastern Japan arc and its relationship to seismic and volcanic activity, Nature, 352, 683-689, 1991.

Hasegawa, A., S. Horiuchi, and N. Umino, Seismic structure of the northeastern Japan convergent margin: A synthesis, J. Geophys. Res., 99, 22295-22311, 1994.

Hasegawa, A., A. Yamamoto, N. Umino, S. Miura, S. Horiuchi, D. Zhao, and $\mathrm{H}$. Sato, Seismic activity and deformation process of the overriding plate in the northeastern Japan subduction zone, Tectonophysics, 319, 225-239, 2000.

Hasegawa, A., H. Ito, T. Iwasaki, and T. Ikawa, Deep structure of NRF as inferred from seismic expeditions, the Proceedings of the International Symposium on Slip and Flow Processes in and Below Seismogenic Region, 67-72, 2001.

Hasegawa, A., J. Nakajima, N. Umino, and S. Miura, Deep structure of the northeastern Japan arc and its implications for crustal deformation and shallow seismic activity, Tectonophysics, 403, 59-75, 2005.

Hori, S., N. Umino, T. Kono, and A. Hasegawa, Distinct S-wave reflectors (bright spots) extensively distributed in the crust and upper mantle beneath the northeastern Japan arc, J. Seismol. Soc. Jpn., 56, 435-446, 2004.

Horiuchi, S., H. Negishi, J. Uchida, M. Kuchiishi, N. Umino, T. Matsuzawa, T. Okada, A. Hasegawa, K. Yoshimoto, Development of high sampling frequency seismic observation system, J. Seismol. Soc. Jpn., 55, 217-222, 2002 (in Japanese).

Iio, Y. and Y. Kobayashi, Is the plastic flow uniformly distributed below the seismogenic region?, Tectonophysics, 364, 43-53, 2003.

Iio, Y., T. Sagiya, and Y. Kobayashi, What controls the occurrence of shallow intraplate earthquakes?, Earth Planets Space, 56, 1077-1086, $2004 a$.

Iio, Y., T. Sagiya, N. Umino, T. Nishimura, K. Takahashi, and T. Homma, A comprehensive model of the deformation process in the NagamachiRifu Fault Zone, Earth Planets Space, 56, 1339-1345, 2004b.

Ikawa, T., T. Kawanaka, S. Kawasaki, A. Hasegawa, N. Umino, A Nakamura, H. Ito, T. Iwasaki, and H. Sato, Seismic reflection survey of the deep structure of Nagamachi-Rifu fault, northeastern Japan, Proceedings of international symposium on slip and flow process in and below 
the seismogenic region, 44, 2001 .

Imanishi, K., H. Ito, Y. Kuwahara, Y. Maeda, T. Yokokura, N. Kano, K. Yamaguchi, and A. Tanaka, Deep structure of the Nagamachi-Rifu fault deduced from small aperture seismic array observation, Earth Planets Space, 54, 1033-1038, 2002.

Ito, H., Outline of the comprehensive joint research on the modeling of slip process of earthquake source fault and plastic flow below the seismogenic region, the Proceedings of the International Symposium on Slip and Flow Processes in and Below Seismogenic Region, 9-10, 2001.

Ji, S., Q. Wang, and B. Xia, Handbook of Seismic Properties of Minerals, Rocks, and Ores, Polytechnique International Press, 630 pp., 2002.

Johnson, P. and T. McEvilly, Parkfield seismicity: Fluid driven?, J. Geophys. Res., 100, 12937-12950, 1995.

Komazawa, M. and M. Mishina, Caldera structure inferred from gravity anomalies west of Nagamachi-Rifu Fault, Northeast Japan, Earth Planets Space, 54, 1049-1053, 2002.

Miyagi Prefectural Government, Research on the Nagamachi-Rifu fault, Abstract for the Results of active fault research supported by Headquarters for Earthquake Research Promotion, No. 1, The Science and Technology Agency, Japan, 30-34, 1997.

Miyagi Prefectural Government, Research on the Nagamachi-Rifu fault, Abstract for the Results of active fault research supported by Headquarters for Earthquake Research Promotion, No. 2, The Science and Technology Agency, Japan, 29-34, 2000.

Nakajima, J. and A. Hasegawa, Tomographic imaging of seismic velocity structure in and around the Onikobe volcanic area, northeastern Japan: implications for fluid distribution, J. Volcanol. Geotherm. Res., 127, 1$18,2003$.

Nakajima, J., T., Matsuzawa, A. Hasegawa, and D. Zhao, Threedimensional structure of $\mathrm{Vp}$, Vs and $\mathrm{Vp} / \mathrm{Vs}$ beneath the northeastern Japan arc: Implications for arc magmatism and fluids, J. Geophys. Res., 106, 21843-21857, 2001a.

Nakajima, J., T., Matsuzawa, A. Hasegawa, and D. Zhao, Seismic imaging of arc magma and fluids under the central part of northeastern Japan, Tectonophysics, 341, 1-17, 2001b.

Nakajima, J., T. Matsuzawa, and A. Hasegawa, Moho depth variation in the central part of northeastern Japan estimated from reflected and converted waves, Phys. Earth Planet Inter., 130, 31-47, 2002.

Nakajima, J., Y. Takei, and A. Hasegawa, Quantitative analysis of the inclined low-velocity zone in the mantle wedge of northeastern Japan: A systematic change of melt-filled pore shapes with depth and its implications for melt migration, Earth Planet. Sci. Lett., 234, 59-70, 2005.

Nakamura, A., Y. Asano, and A. Hasegawa, Estimation of deep fault geometry of the Nagamachi-Rifu fault from seismic array observations, Earth Planets Space, 54, 1027-1031, 2002.

Nakamura, K., Inversion tectonics and its structural expression, J. Tectonic Res. Group Jpn., 38, 3-45, 1992 (in Japanese with English abstract).

Nishimura, T., T. Sagiya, and S. Miura, Crustal deformation around the Nagamachi-Rifu fault zone and its vicinity (central Tohoku), northeastern Japan, observed by a continuous GPS network, J. Seismol. Soc. Jpn., 56, 497-509, 2004.

Ogawa, Y., M. Mishina, Y. Honkura, K. Takahashi, and S. B. Tank, Electromagnetic imaging of the Nagamachi-Rifu fault and its deep extension, The Second International Symposium on Slip and Flow Processes in and below the Seismogenic Region, 2004.

Okada, T., A study on characteristics of seismicity and asperities in the northeastern Japan arc, Doctoral Dissertation, Tohoku University, Sendai, Japan, 2003 (in Japanese).

Okada, T., U. Umino, Y. Ito, T. Matsuzawa, A. Hasegawa, and M. Kamiyama, Source processes of 15 September 1998 M5.0 Sendai, northeastern Japan, earthquake and its M3.8 foreshock by waveform inversion, Bull. Seismol. Soc. Am., 91, 1607-1618, 2001.
Okada, T., N. Umino, T. Matsuzawa, J. Nakajima, N. Uchida, T. Nakayama, S. Hirahara, T. Sato, S. Hori, T. Kono, Y. Yabe, K. Ariyoshi, S. Gamage, J. Shimizu, J. Suganomata, S. Kita, S. Yui, M. Arao, S. Hondo, T. Mizukami, H. Tsushima, T. Yaginuma, A. Hasegawa, Y. Asano, H. Zhang, and C. Thurber, Aftershock distribution and 3D seismic velocity structure in and around the focal area of the $2004 \mathrm{mid}$ Niigata prefecture earthquake obtained by applying double-difference tomography to dense temporary seismic network data, Earth Planets Space, 57, 435-440, 2005.

Okamura, Y., M. Watanabe, E. Morijiri, and M. Satoh, Rifting and basin inversion in the eastern margin of the Japan Sea, Island Arc, 4, 166-181, 1995.

Pervukhina, M., Y. Kuwahara, and H. Ito, Rock microstructure in the deep extension of the Nagamachi-Rifu fault revealed by analysis of collocated seismic and magnetotelluric data: Implication of strong deformation process, Earth Planets Space, 56, 1357-1368, 2004.

Sato, H., The relationship between late Cenozoic tectonic events and stress field and basin development in northeast Japan, J. Geophys. Res., 99, 22261-22274, 1994.

Sato, H., T. Imaizumi, T. Yoshida, H. Ito, and A. Hasegawa, Tectonic evolution and deep to shallow geometry of Nagamachi-Rifu active fault system, NE Japan, Earth Planets Space, 54, 1039-1043, 2002.

Takei, Y., Effect of pore geometry on Vp/Vs: From equilibrium geometry to crack, J. Geophys. Res., 107(B2), 2043, 2002.

Thurber, C. H., S. Roecker, K. Roberts, M. Gold, L. Powell, and K. Rittger, Earthquake locations and three-dimensional fault zone structure along the creeping section of the San Andreas fault near Parkfield, CA: Preparing for SAFOD, Geophys. Res. Lett., 30(3), 1112, 2003.

Umino, N., T. Okada, and A. Hasegawa, Foreshock and aftershock sequence of 1998 M5.0 Sendai, northeastern Japan, earthquake and its implications for earthquake nucleation, Bull. Seismol. Soc. Am., 92, 24652477, 2002a.

Umino, N., H. Ujikawa, S. Hori, and A. Hasegawa, Distinct S-wave reflectors (bright spots) detected beneath the Nagamachi-Rifu fault, NE Japan, Earth Planets Space, 54, 1021-1026, 2002 b.

Wessel, P. and W. H. F. Smith, New, improved version of the Generic Mapping Tools released, EOS Trans. AGU, 79, 579, 1998.

Yoshida, T., The evolution of arc magmatism in the NE Honshu arc, Japan, Sci. Rep. Tohoku Univ., 36, 131-149, 2001.

Yoshimoto, K., N. Uchida, H. Sato, M. Ohtake, N. Hirata, and K. Obara, Microseismicity around the Nagamachi-Rifu fault, Miyagi Prefecture, Northeastern Japan, J. Seismol. Soc. Jpn, 52, 407-416, 2000 (in Japanese with English abstract).

Zhao, D., S. Horiuchi, and A. Hasegawa, 3-D seismic velocity structure of the crust and uppermost mantle in the northeastern Japan arc, Tectonophysics, 181, 135-149, 1990.

Zhao, D., A. Hasegawa, and S. Horiuchi, Tomographic imaging of P and $\mathrm{S}$ wave velocity structure beneath northeastern Japan, J. Geophys. Res., 97, 19909-19928, 1992.

Zhao, D., H. Kanamori, and H. Negishi, Tomography of the source area of the 1995 Kobe earthquake: evidence for fluids at the hypocenter?, Science, 274, 1891-1894, 1996.

Zhao, D., T. Matsuzawa, and A. Hasegawa, Morphology of the subducting slab boundary in the northeastern Japan arc, Phys. Earth Planet. Inter., 102, 89-102, 1997.

Zhao, D., H. Tani, and O. P. Mishra, Crustal heterogeneity in the 2000 Western Tottori earthquake region: effect of fluids from slab hydration, Phys. Earth Planet. Inter., 145, 161-177, 2004.

J. Nakajima (e-mail: nakajima@aob.geophys.tohoku.ac.jp), A. Hasegawa, S. Horiuchi, K. Yoshimoto, T. Yoshida, and N. Umino 